\title{
KOLABORASI FISH-NET DAN TECHNOLOGY UNTUK OPTIMALISASI ALAT TANGKAP IKAN
}

\author{
Irwan Ardiansyah ${ }^{1}$, Sulfikar $^{2}$, Winarto Surachmad ${ }^{3}$, Lilis Nur Hayati ${ }^{4}$ \\ 1irwan.ardyansah75@gmail.com, ${ }^{2}$ fhikarzul18@gmail.com, ${ }^{3}$ win7sure@gmail.com, \\ ${ }^{4}$ lilis.nurhayati@umi.ac.id \\ Universitas Muslim Indonesia
}

\begin{abstract}
Abstrak
Kelurahan Untia merupakan salah satu daerah yang ditempati bermukim oleh para nelayan dan juga mayoritas penduduknya berprofesi sebagai nelayan perikanan tangkap. Alat tangkap yang dominan digunakan nelayan di kelurahan Untia yaitu surface gill net. Namun penggunan alat tangkap surface gill net ini dinilai masih belum efektif dan efisien karena mempunyai kendala pada proses pengecekan jaring, proses penangkapan ikan yang lama, jaring cenderung hilang, dan hasil tangkapan yang dinilai kurang. Maka dari permasalahan itu, mendorong kami untuk membuat sebuah inovasi teknologi tepat guna yang bernama FiNe-Tech (Fish Net Technology). FiNe-Tech dirancang agar mampu memonitoring ikan yang terjerat di alat tangkap surface gill net, mempermudah proses penangkapan ikan di laut, melacak posisi jarring, mempercepat proses penangkapan ikan, dan meningkatkan hasil tangkapan jaring melalui sebuah aplikasi smartphone dengan jarak dekat maupun jarak jauh dari posisi jaring walaupun kita ada di rumah sekalipun.
\end{abstract}

Kata kunci: Surface Gill Net, FiNe-Tech, Alat Tangkap, Proses Penangkapan, Hasil Tangkapan.

\begin{abstract}
Kelurahan Untia is one of the areas occupied by the fishermen and also the majority of the population work as fishermen catch fishermen. The dominant fishing gear used by fishermen in the village of Untia is surface gill net. But the use of surface gill net capture device is considered not effective and efficient because it has constraints on the process of checking the net, the old fishing process, the net tends to disappear, and the catch is considered less. So from that problem, we encourage us to create a technological innovation called FiNe-Tech (Fish Net Technology). FiNe-Tech is designed to be able to monitor fish trapped in surface gill net captures, simplify the process of catching fish in the sea, tracking the position of the jarring, speeding up the fishing process, and increasing the net catch through a smartphone application at close range and distance from the position nets even though we are at home though.
\end{abstract}

Keywords: Gill Net Surface, FiNe-Tech, Fishing Equipment, Catching Process, Catch.

\section{Pendahuluan}

Sub sektor perikanan air laut Indonesia memiliki potensi yang sangat besar bagi Indonesia. Hal ini mengingat wilayah Indonesia merupakan negara kepulauan terbesar di dunia, yang mempunyai luas lautan total mencapai 5,8 juta $\mathrm{km} 2$ dan memiliki garis pantai sepanjang $104.000 \mathrm{~km}$ dengan jumlah pulau sebanyak 17.504[1]. Kota Makassar merupakan salah satu kota pesisir di Sulawesi Selatan yang memiliki banyak daerah-daerah yang ditempati bermukim oleh para nelayan seperti contohnya di kelurahan Untia, kecamatan Biringkanaya, kota Makassar.

Kelurahan Untia merupakan salah satu wilayah yang dijadikan bermukim oleh para nelayan karena mempunyai potensi perikanan tangkap yang dinilai besar dan sangat berpengaruh terhadap pendapatan masyarakat. Berdasarkan lokasi melaut, nelayan Untia tergolong menjadi tiga, yaitu (1) nelayan lokal yang melaut di sekitar kota Makassar; (2) nelayan yang melaut antar kabupaten/provinsi, (3) nelayan yang melaut antar negara mengikuti kapal asing[2].

Alat tangkap surface gill net atau biasa disebut jaring insang, dimana Surface gill net yaitu alat penangkap ikan yang terbuat dari bahan jaring, berbentuk empat persegi panjang dengan ukuran mata jaring yang sama, dioperasikan pada bagian dasar perairan dengan sasaran penangkapan adalah ikan demersal[3]. Alat tangkap surface gill net ini dinilai alat tangkap yang sangat berpotensial, hal ini dapat dilihat dari jumlah alat yang meliputi 145.685 unit dengan produksi 477.201 ton dari seluruh alat tangkap secara nasional menurut Ditjenkan (1986).

Namun alat tangkap ini masih mempunyai kendala sehingga perlu untuk diselesaikan, yaitu pada proses pengecekan jaring secara manual. Para nelayan juga harus menunggu $5-6$ jam di lautan agar jaring dapat dipenuhi oleh ikan yang terjerat. Selain itu, lokasi jaring yang dibentang sulit untuk 
ditemukan apabila jaring yang dibentang terbawa oleh arus atau sedang ditinggalkan. Namun kendala yang lebih perlu untuk diselesaikan adalah tingkat hasil tangkapan yang dinilai masih kurang.

Berdasarkan permasalahan diatas, diinisialisasikanlah sebuah inovasi teknologi tepat guna yang bernama FiNe - Tech (Fish Net and Technology). FiNe - Tech dirancang agar mampu memonitoring tingkat kepadatan ikan[4] yang terjerat di alat tangkap surface gill net hanya dengan menggunakan aplikasi pada smartphone dan platform sms gateway. Pada teknologi FiNe - Tech ini juga mempunyai komponen pemanggil dan penarik perhatian ikan sehingga hal ini dapat meningkatkan hasil tangkapan nelayan dengan waktu yang relatif lebih cepat.

Penginisialisasian teknologi ini dilakukan dengan beberapa tahap yaitu tahap persiapan, tahap perancangan dan pembuatan, tahap pengujian dan evaluasi, dan terakhir tahap pengenalan dan penerapan. Adapun target khusus dari pelaksanaan program ini yaitu dengan menggunakan teknologi FiNe-Tech dapat meningkatkan hasil tangkapan nelayan, memudahkan dalam pengecekan dan memonitoring jaring, dan mempercepat proses penangkapan ikan nelayan secara efektif dan efisien.

Dengan adanya inovasi teknologi ini mampu menyelesaikan permasalahan proses penangkapan ikan yang dihadapi para nelayan di Indonesia, khususnya di kelurahan Untia, maka dengan adanya solusi inovasi teknologi yang bernama FiNe - Tech, hal tersebut dapat teratasi dan kemudian akan memberikan dampak terhadap peningkatan perekonomian di Indonesia di sektor perikanan dan kelautan.

\section{Metode}

\subsection{Perancangan proses}

Tahap perancangan proses dimulai dengan pembuatan flowchart, diantaranya alur kerja teknologi FiNe-Tech, alur kerja SMS Gateway dan alur kerja Aplikasi.

\subsubsection{Alur Kerja Teknologi FiNe-Tech}

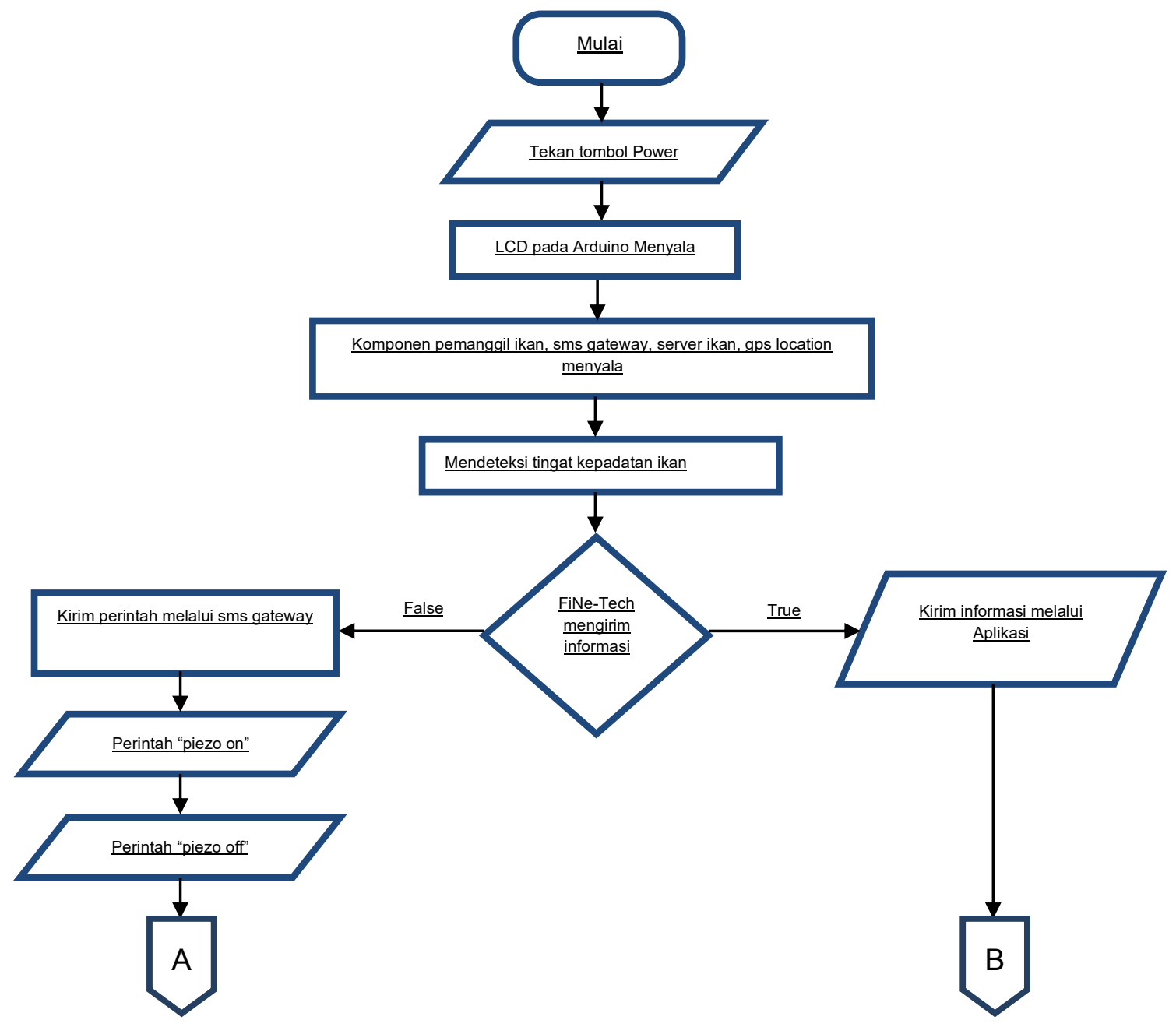




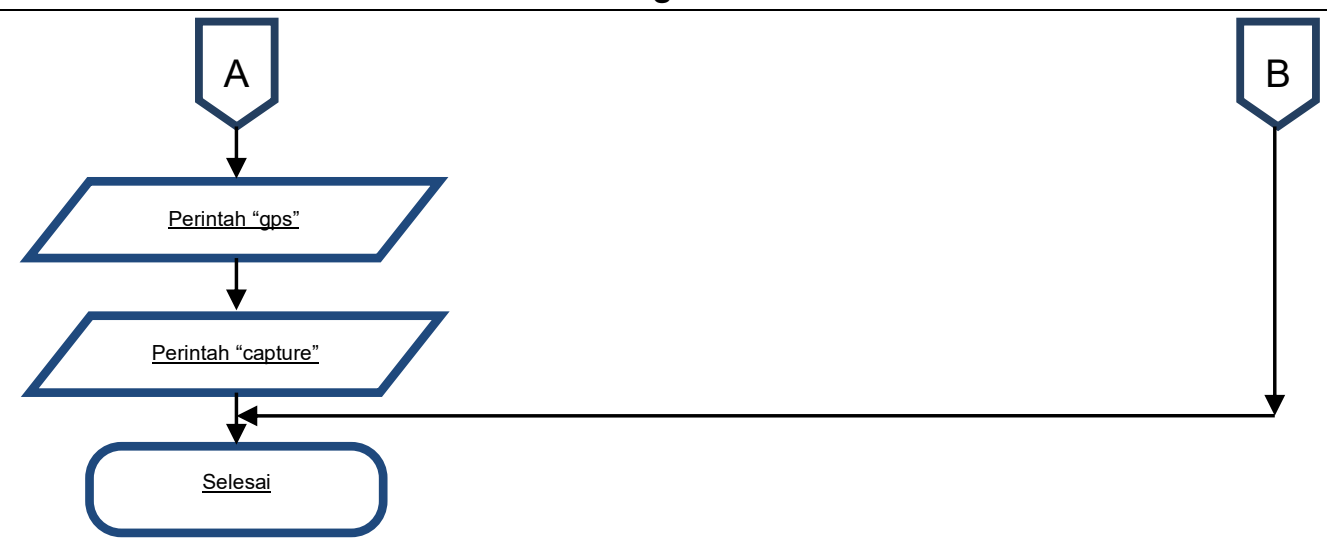

Gambar 1. Flowchart Teknologi FiNe-Tech

Gambar 1 menunjukkan bahwa Teknologi FiNe-Tech aktif ditandai dengan nyalanya LCD Monitor setelah menekan tombol Power. Kemudian Komponen pun ikut aktif. Setelah itu FiNe-Tech mulai bekerja dengan mendeteksi tingkat kepadatan ikan dan menandai lokasi. Hasil dari pendeteksian tingkat kepadatan dan lokasi jaring akan mengeluarkan output berupa informasi yang dikirim melalui SMS Gateway atau Aplikasi secara otomatis. Khusus untuk SMS Gateway diharuskan untuk memberi perintah untuk menampilkan informasi tersebut. Serta dapat pula memberikan perintah untuk mengaktifkan beberap komponen yang dianggap perlu.

\subsubsection{Alur Kerja Aplikasi}

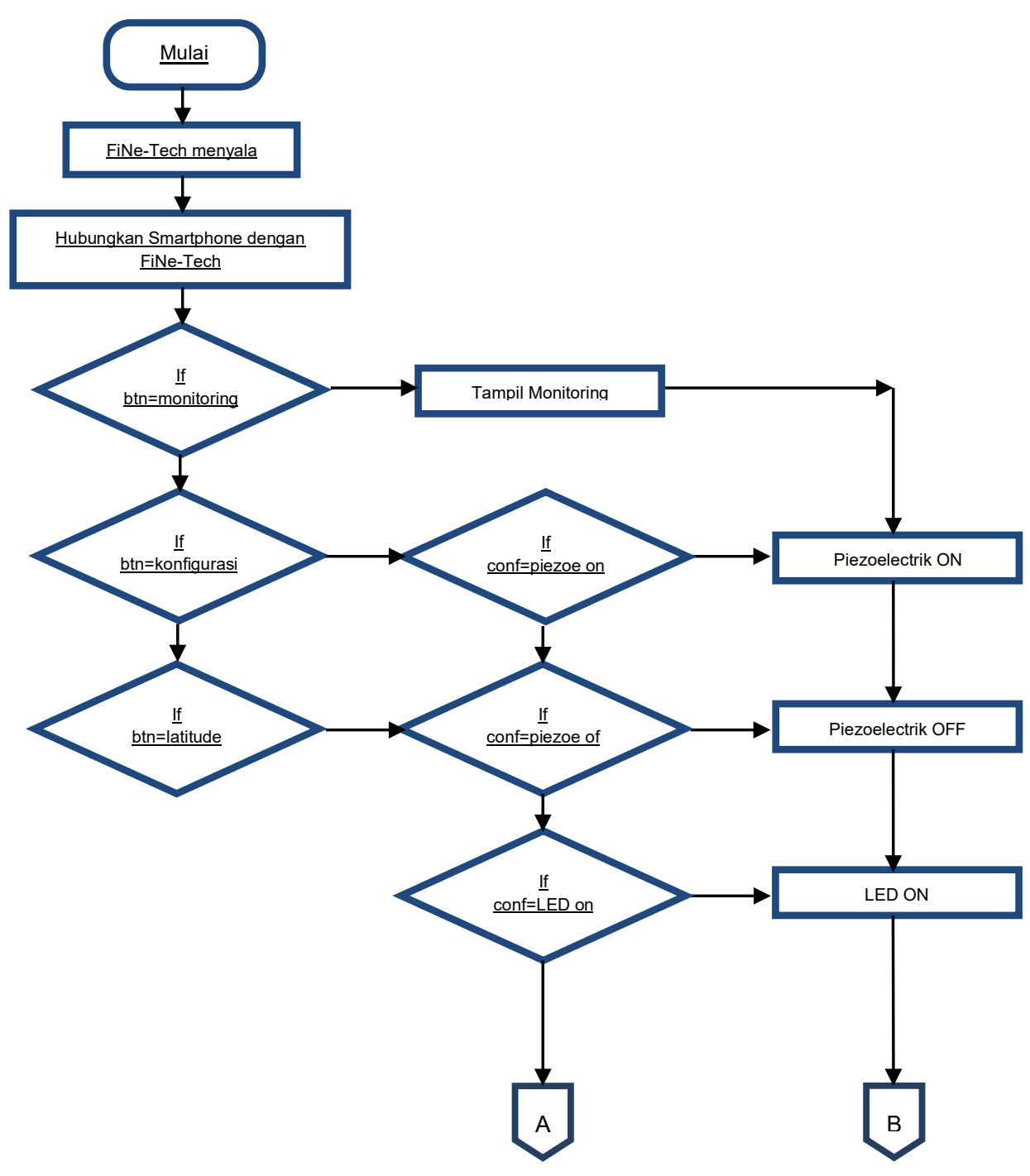




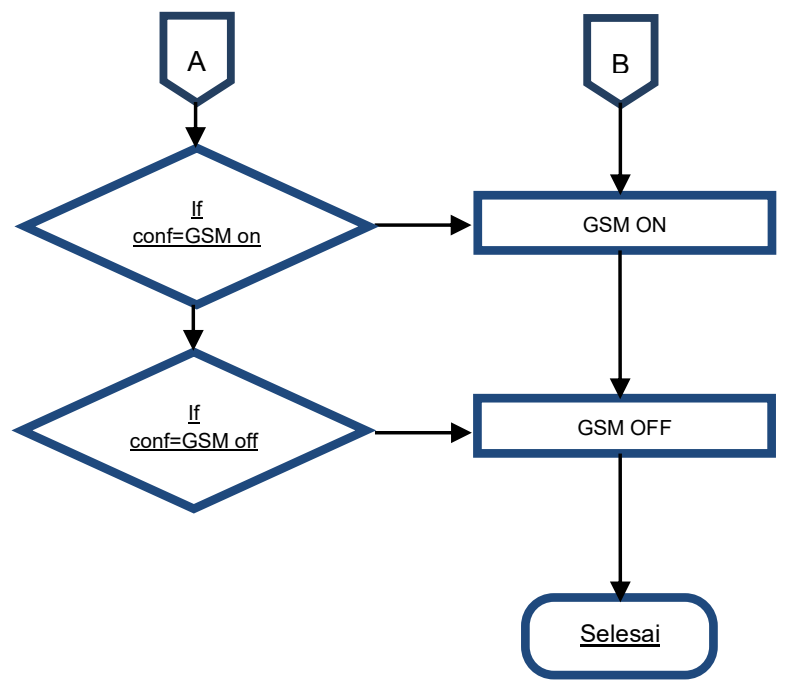

Gambar 2. Flowchart Alur Kerja Aplikasi

\subsection{Pembuatan Alat}

Gambar 2 menjelaskan rancangan komponen dari teknologi FiNe-Tech yang terdiri dari Piezoelectric Buzzer, GPS Module, SIM800L, WiFi Module, LED Ikan dan Raspberry PI. Semua komponen yang disebutkan dihubungkan melalui Breadboard dan di buatkan program yang ditunjukkan pada Gambar 3 agar komponen berfungsi dan saling berelasi. Program tersebut kemudian ditanamkan di mikrokontroller Arduino Uno. Setelah itu, memasang komponen tersebut didalam Casebox yang terdiri 2 bagian yaitu bagian penyimpanan komponen dan bagian penyimpanan daya. Digunakan sambungan USB untuk menghubungkan antara komponen dan daya agar komponen tersebut mendapat tenaga listrik. Pemasangan Sensor ultrasonic di luar casebox dimaksudkan agar komponen ini dapat leluasa mendeteksi tingkat kepadatan ikat dengan digunakannya penggaris sebagai penopang dan selang agar tidak kemasukan air pada saat ditenggelamkan.

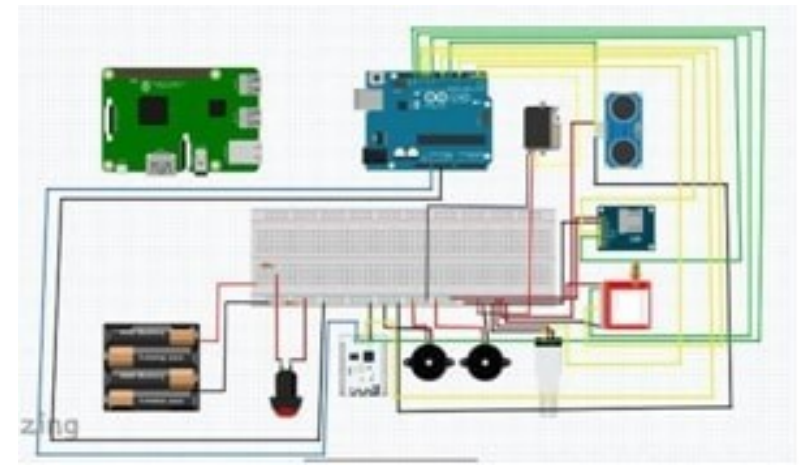

Gambar 3. Perancangan rangkaian

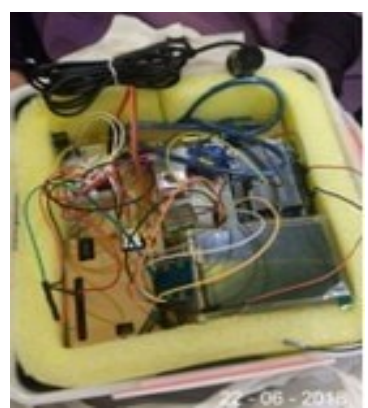

Gambar 5. Penempatan komponen

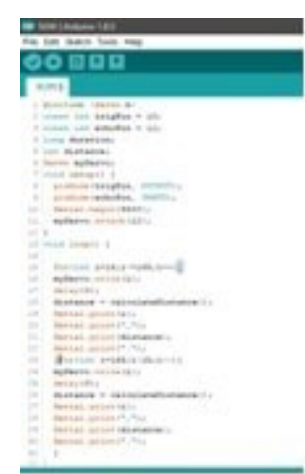

Gambar 4. Pembuatan program

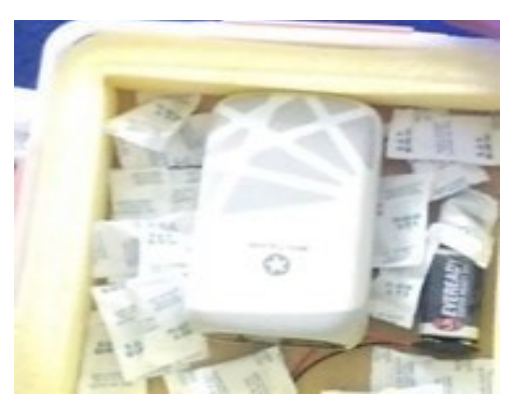




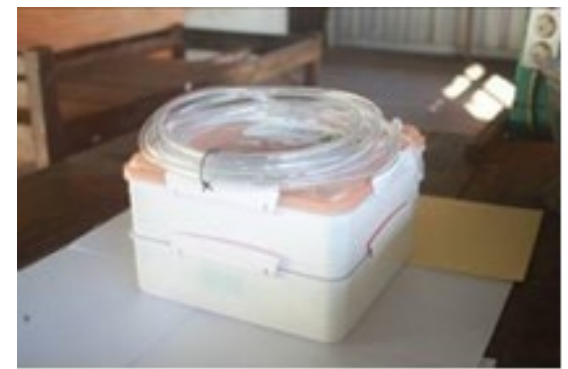

Gambar 7. Casebox Waterproof

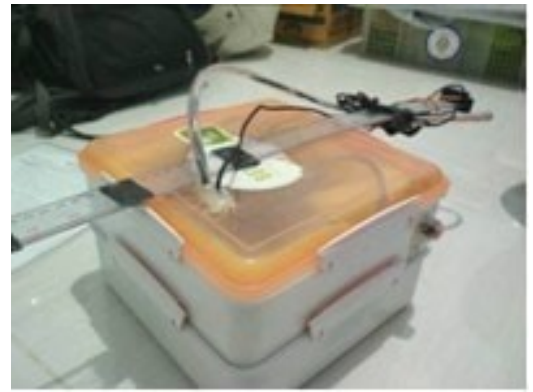

Gambar 8. Teknologi FiNe-Tech siap digunakan

\subsection{Pembuatan Aplikasi}

Pembuatan aplikasi ini menggunakan tools Android Studio sebagai salah satu software pembuatan aplikasi Android. Pada tahap ini dilakukan pembuatan interface yang terdiri dari beberapa menu yang yang akan disimpan dalam ekstensi (.xml). Untuk memberikan fungsi pada menu tersebut, dibuatkan program yang akan disinkronkan melalui variable-variabel dan akan disimpan dalam ektensi (.java). Setelah pembuatan interface dan program, akan dilakukan diubah dalam bentuk (.apk) yang mendukung file penginstalan aplikasi pada sistem Android.

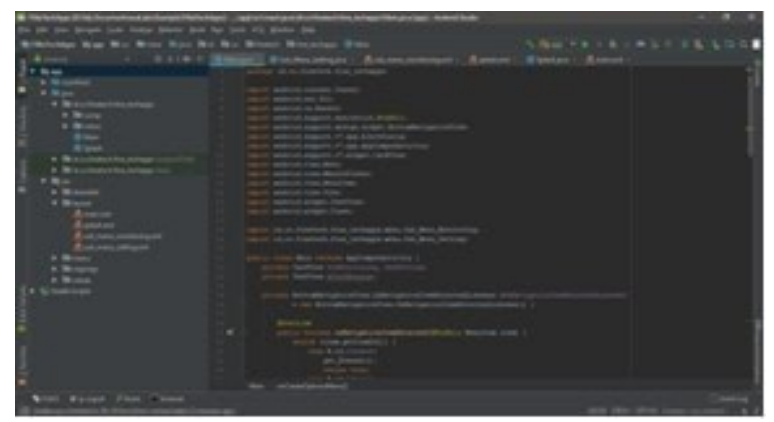

Gambar 9. Pembuatan aplikasi

\section{Hasil dan Pembahasan}

\subsection{Antarmuka Aplikasi}

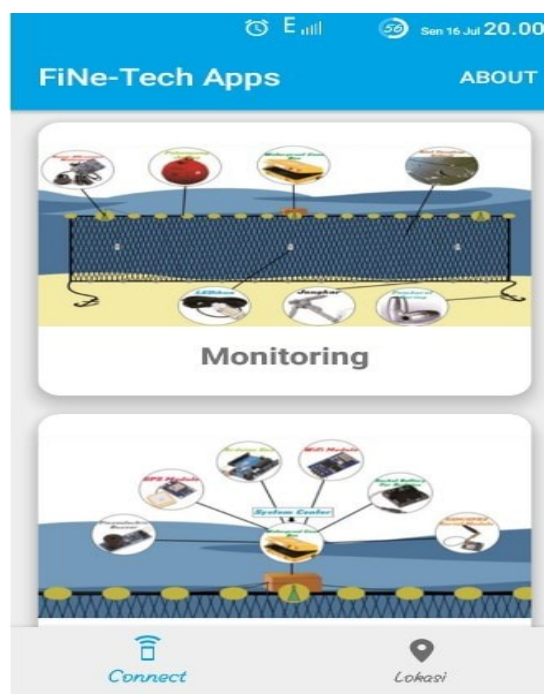


Gambar 10. Interface Utama Aplikasi

Gambar 9. merupakan user interface dari frame utama aplikasi. Pada gambar terlihat ada 2 menu yang dapat dipilih user yaitu monitoring dan konfigurasi. Pada menu monitoring, akan tampil informasi mengenai kondisi jaring baik itu tingkat kepadatan maupun komponen yang sedang aktif. Dan pada bagian konfigurasi, akan menampilkan komponen-komponen yang bisa dikontrol on/off-nya.

\subsection{Pengujian LED ikan}

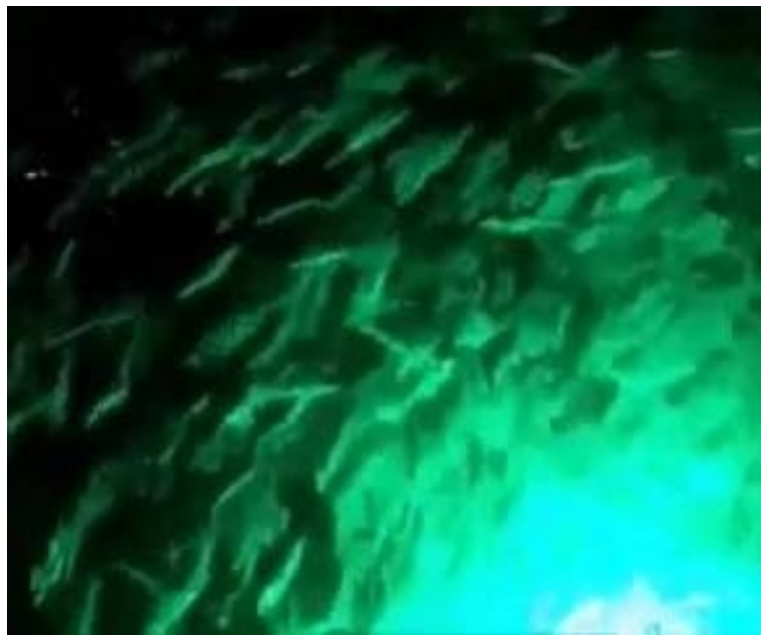

Gambar 11. Pengujian LED ikan di laut

Gambar 10. diatas menunjukkan ikan yang berhasil mendekati komponen LED ikan yang ada pada FiNe-Tech dengan rentan waktu 30 - 50 menit. Rekayasa LED ikan untuk mengumpulkan sekumpulan ikan mempunyai variasi panjang gelombang yaitu led putih (600 $\mathrm{nm})$, biru (465-500 nm), hijau (500-520 nm) dan amber (595-605 nm)[5]. Lampu yang digunakan yaitu berwarna hijau dengan tingkat intensitas seperti yang ditunjukkan pada gambar 11. ketika lampu sedang berada dibawah air.

\section{Electromagnetic spectrum of sunlight}

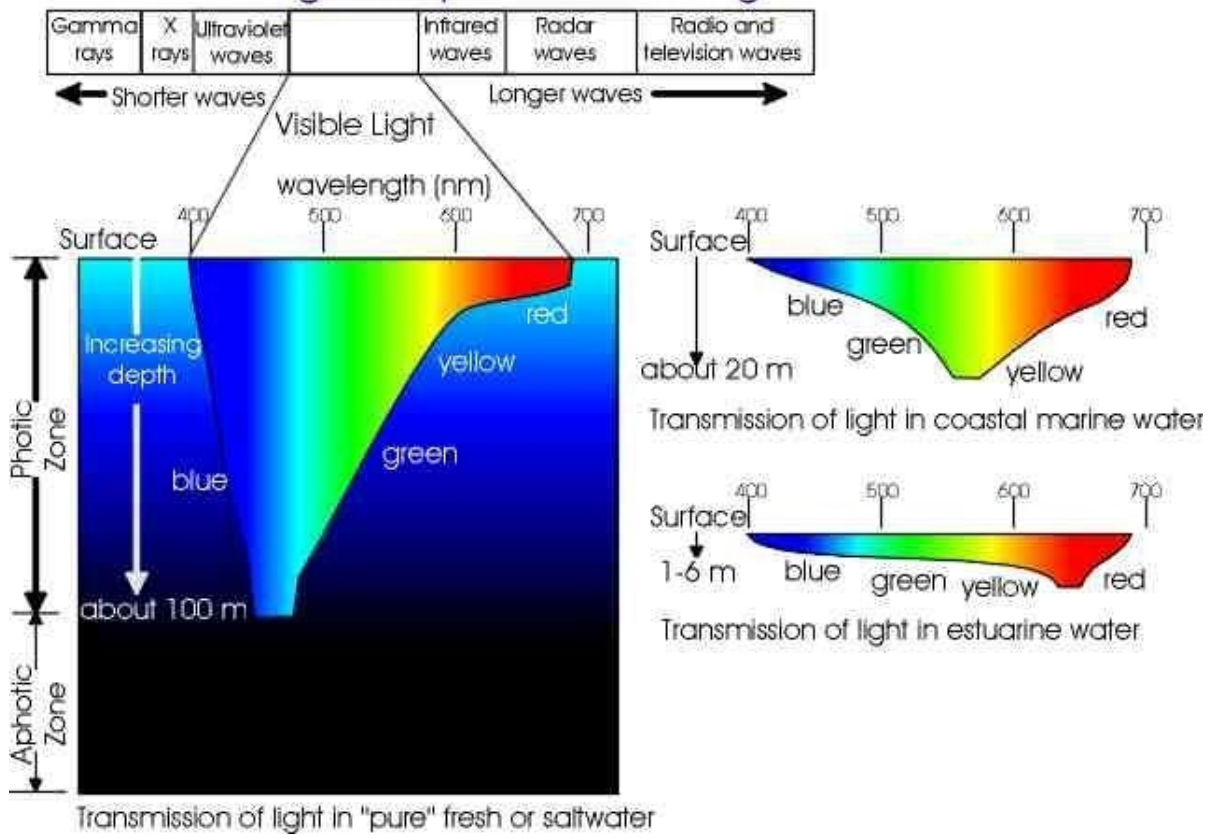

Gambar 13. Intensitas cahaya berwarna di dalam laut 


\subsection{Pengujian Global Positioning System (GPS)}

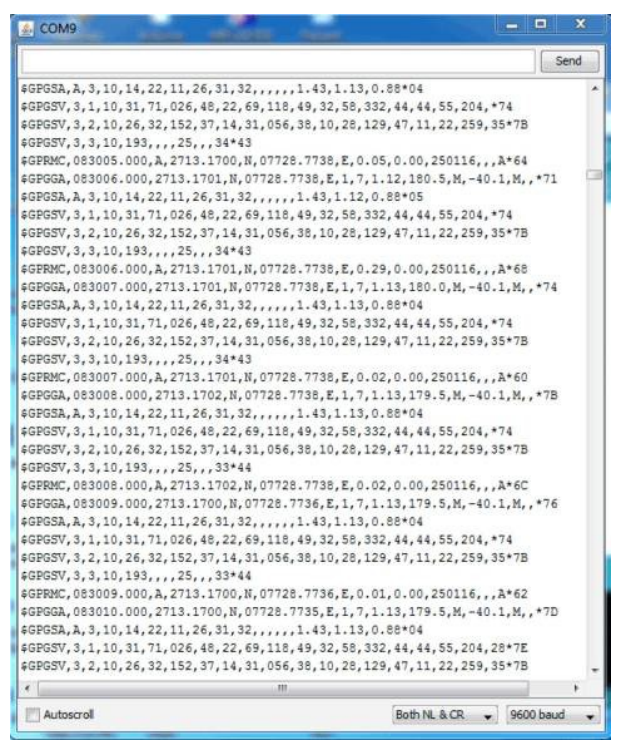

Gambar 14. Tampilan Komponen GPS memberikan titik kordinat

Pada gambar 12. Menunjukkan komponen GPS module yang berada pada FiNe-Tech memberikan titik kordinat latitude dan longitude yang bisa dikonversi di aplikasi Gmaps smartphone. Pemberian titik kordinat ini diberikan ketika melakukan request terhadap mikrokontroller FiNe-Tech.

\subsection{Grafik Sesudah Penggunaan FiNe-Tech}

\section{Grafik Sebelum dan Sesudah Pemakaian Teknologi FiNe-Tech}

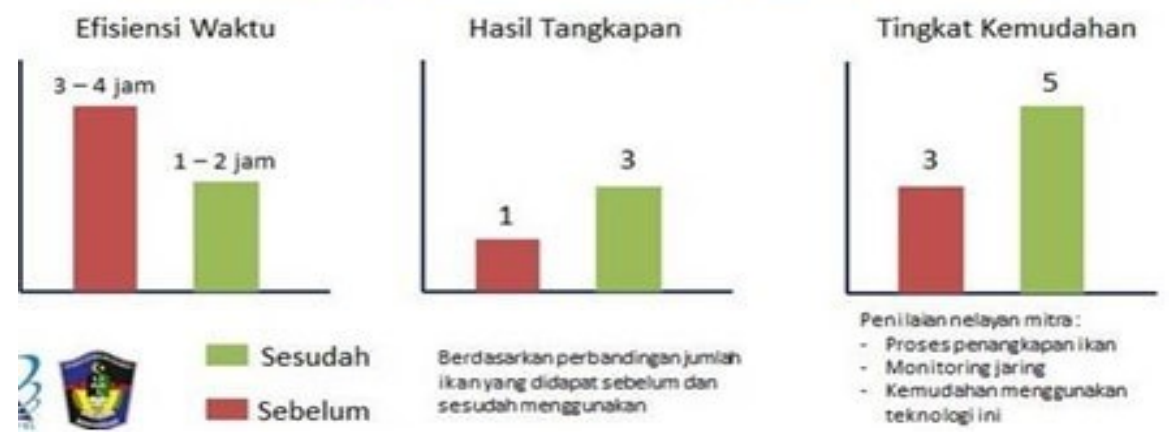

\section{Gambar 15. Grafik Pengujian}

Teknologi FiNe-Tech memberikan pengaruh positif terhadap para nelayan keluraha Untia. Dimana sesudah memakai teknologi FiNe-Tech, para nelayan hanya membutuhkan waktu 1 2 jam untuk proses penangkapan ikan di laut, yang sebelumnya memakan waktu $3-4$ jam. Hasil tangkapan nelayan juga ikut meningkat 3 kali lebih banyak, dimana indikator ini didapatkan dari jumlah ikan yang didapatkan sebelum menggunakan FiNe-Tech dan sesudah menggunakannya. Kemudahan dalam memonitoring jaring juga dirasakan oleh si nelayan ketika menggunakan FiNe-Tech ini, cukup dengan menggunakan handphone atau smartphone untuk mengetahui tingkat kepadatan ikan yang terjerat baik secara jarak jauh maupun jarak dekat. Untuk mengetahui lokasi jaring yang dibentang di lautan juga sangat memudahkan para nelayan, pasalnya ketika pergi meninggalkan jaring yang dibentang, sulit untuk menemukannya kembali apalagi tanda yang dipasangkan tidak terlalu kelihatan. 


\section{Kesimpulan dan Saran}

\subsection{Kesimpulan}

Berdasarkan hasil dan pembahasan diatas, disimpulkan bahwa teknologi FiNe-Tech dapat memberikan kemudahan para nelayan kelurahan Untia pada saat proses penangkapan ikan di laut dimana teknologi ini dapat menarik perhatian ikan sehingga mendekat ke jaring serta dapat mengetahui posisi jaring yang berada di laut melalui smartphone sehingga pengkapan dapat mengefesiensikan waktu dan menambahnya jumlah tangkapan ikan.

\subsection{Saran}

Pengembangan teknologi selanjutnya mendeteksi jumlah ikan yang terjerat pada jaring surface gillnet.

\section{Ucapan Terima Kasih}

Terima kasih kepada Kementrian Riset dan Teknologi yang telah mendanai keberlangsungan penelitian ini, serta tak lupa juga kami ucapkan terima kasih kepada mitra kami yang telah bersedia meluangkan waktunya untuk membantu dalam proses program pelaksanaan ini.

\section{Daftar Pustaka}

[1] M. S. Prof. Dr. Ir. H. Tridoyo Kusumastanto, "Pemberdayaan Sumberdaya Kelautan, Perikanan Dan Perhubungan Laut Dalam Abad Xxi," Inst. Pertan. Bogor, vol. 1, no. 2, pp. 1-48, 2003.

[2] A. Akil, A. Yudono, and S. Nurvita, "PERANAN LINGKUNGAN BARU MEMBENTUK MASYARAKAT DAN PERMUKIMAN : BELAJAR DARI RESETTLEMENT KELURAHAN UNTIA UNTUK PERENCANAAN PERMUKIMAN NELAYAN DI KOTA MAKASSAR," vol. 1, no. September, pp. 1-10, 2015.

[3] B. Gillnet, D. I. Perairan, and D. Sanjai, "KECAMATAN SINJAI TIMUR KABUPATEN SINJAI STUDI RNCANG BANGUN JARING INSANG DASAR ( BOTTOM GILLNE ) DI PERAIRAN DESA SANJAI," 2017.

[4] S. Hartini, A. D. Sasanti, F. H. Taqwa, and A. Bahan, "Kualitas air, kelangsungan hidup dan pertumbuhan benih ikan gabus (," vol. 1, no. 2, pp. 192-202, 2013.

[5] A. Cahyadi and X. You, "Rekayasa Led Ikan Melalui Pengaturan Lumensi Cahaya Berbasis Perangkat Lunak Versi Betha Arrangement of Led Lumen Based on Pulse Width Modulation ( Pwm ) Betha Version To Attract the Schooling Fish," pp. 119-125, 2017. 